\title{
Análise do Tratamento Legal conferido aos Casos de Acidentes e Enfermidades Laborais no Brasil
}

\author{
Treatment legal analysis given to Accident Cases and Disability \\ Employment in Brazil
}

\section{Análisis el tratamiento legal dado a los casos de accidentes y Empleo para Discapacitados en Brasil}

\author{
Jacyara Farias Sousa, Dr ${ }^{\mathrm{a}}$ \\ Professora Adjunta da Unidade \\ Acadêmica de Direito - UFCG \\ Rodovia, Antônio Mariz, BR-230, \\ KM466, CEP: 58.800-120, Sousa, PB, \\ Brasil, e-mail: jacyfarias@gmail.com
}

\author{
Jônica Marques Coura Aragão, Dr \\ Professora Adjunta da Unidade \\ Acadêmica de Direito - UFCG \\ Rodovia, Antônio Mariz, BR-230, \\ KM466, CEP: 58.800-120, Sousa, PB, \\ Brasil, e-mail: \\ jonicamca@gmail.com
}

\author{
Richard Weiny Aragão, Esp. \\ Instituto Federal de Educação da \\ Paraíba, Especialista em Gestão Pública \\ Rua Presidente Tancredo Neves, s/n, \\ Jardim Sorrilândia, Sousa/PB \\ CEP : 58800-970, Fone: (83) 3522-2727, e- \\ mail: richardaragao@hotmail.com
}

\section{RESUMO}

O artigo analisa o tratamento legal conferido aos casos de acidentes e enfermidades laborais no Brasil, quanto às medidas profiláticas, punitivas e reparatórias na ocorrência de dano. As medidas de medicina e segurança do trabalho foram durante muito tempo relegadas a um segundo plano nos ordenamentos jurídicos mundiais e somente com a modificação das políticas econômicas dos Estados e adoção de vertentes intervencionistas garantidoras dos direitos sociais, os países passaram a adotálas. Para tanto, o objetivo é analisar os fatores que levam a baixa efetividade das normas preventivas e punitivas quanto aos acidentes e enfermidades laborais no Brasil. Realiza-se mediante o emprego do método de abordagem hipotético-dedutivo, utilizando as técnicas de pesquisa bibliográfica e documental. Verificou-se com a realização da pesquisa a ocorrência de uma evolução marcante dos mecanismos legais preventivos, punitivos e reparatórios aos infortúnios laborais, embasada tanto pela legislação pátria, quanto pela adoção de Tratados e Convenções Internacionais pelo Brasil, além das medidas propostas pela OIT e a OMS. Mesmo com esse quadro de significativo avanço relacionado ao tratamento jurídico conferido aos infortúnios do trabalho no Brasil, verifica-se ainda uma legislação difusa e esparsa nessa área, fato que, muitas vezes dificulta a sua aplicabilidade.

Palavras-chave: Acidentes laborais. Legislação difusa. Efetividade.

\section{ABSTRACT}

The article analyzes the legal treatment imputed to cases of accidents and sickness of jobs in Brazil, in relation at prophylactic, punitive and reparatory actions in case of damage. The actions of medicine and security of employment it has been relegated for a long time low priority in global laws and just with changes in economic policies of countries and adoption of interventionist action that insure the social rights, the countries began to adopt them. Therefore, the objective is to analyze the factors that influence to low effectiveness of preventive and punitive rules regarding accidents and insdustrial diseases in Brazil. The study was conducted by employing the method of hypothetical-deductive approach, using the techniques of search in literature and documents. It was observed a high evolution in laws that aim prevent, punish and repair labor's damage through treaties and 
international conventions by Brazil and recommended measures by OIT and OMS. But, despite this significant advance related to laws for protect the job in Brazil, there is still a diffuse and sparse legislation in this area, a fact that often hampers its applicability.

Keywords: Accidents of jobs. Diffuse legislation. Effective.

\section{RESUMEN}

En este artículo se analiza el tratamiento legal dado a los casos de accidentes y enfermedades profesionales en el Brasil, por las medidas profilácticas, punitivas y correctivas en caso de daños. Las medidas de médico y de seguridad durante mucho tiempo han sido relegados a un segundo plano en los sistemas jurídicos del mundo y sólo con los cambios en las políticas económicas de los Estados y la adopción de garantes aspectos intervencionistas de los derechos sociales, los países comenzaron a adoptarlas. Por lo tanto, el objetivo es analizar los factores que conducen a la baja eficacia de las normas preventivas y punitivas sobre los accidentes laborales y las enfermedades en el Brasil. Se lleva a cabo mediante el uso del método hipotético-deductivo de enfoque, utilizando las técnicas de investigación bibliográfica y documental. Fue con la investigación de la ocurrencia de un desarrollo relevante de mecanismos legales preventivas, punitivas y reparatorias a los problemas laborales, basadas tanto en la legislación brasileña, como la aprobación de los tratados y convenios internacionales en Brasil, además de las medidas propuestas por la OIT y QUIEN. Incluso con este avance significativo por encima en relación con el tratamiento legal dado a los problemas laborales en Brasil, también hubo una difusa y dispersa legislación en la materia, un hecho que a menudo dificulta su aplicabilidad.

Palabras clave: Accidentes de trabajo. Legislación difusa. Eficacia.

\section{INTRODUÇÃO}

É sabido que a evolução da sociedade perpassou pela difusão das relações de trabalho. A priori, as atividades laborais eram executadas de forma braçal, sem a utilização de nenhuma tecnologia. Essa situação somente se modificou com o surgimento dos denominados direitos sociais e a eclosão da Revolução Industrial. Por meio desta, as atividades laborais passaram a ser realizadas através do vapor como força volante. Esse foi um fator determinante para a modificação das relações sociais, e especificamente as laborais.

Nos primórdios da atividade de trabalho mecanizada não se pensava em prevenção contra os acidentes e enfermidades laborais, nem no estabelecimento de políticas e práticas preventivas, punitivas e reparadoras a tais condutas. Somente com a evolução do sistema capitalista e a expansão dos meios de produção, os infortúnios do trabalho passaram a constituir um entrave constante para a produtividade, uma vez que afastava o operário da máquina e indiretamente também do consumo. Esses fatores aliados ao processo de evolução da sociedade fomentaram o nascimento de ações preventivas e repressivas para os efeitos das patologias laborais. Merece também destaque a influência que o meio ambiente do trabalho oferta na prevenção dos infortúnios laborais e o conjunto de medidas de cunho administrativo e judicial adotadas pelo Brasil.

A justificativa da pesquisa é demonstrada já que os acidentes e enfermidades laborais acompanham a evolução da sociedade, mas foram durante muito tempo 
relegados a um segundo plano nos ordenamentos jurídicos mundiais. Com a modificação das políticas econômicas dos Estados e adoção de vertentes intervencionistas garantidoras dos direitos sociais, os países passaram a revestir-se de uma atitude positiva no sentido de adotar as condutas profiláticas e punitivas, de cunho administrativo e judicial quanto aos acidentes e enfermidades laborais. Além de, modernamente, acatar as normas regulamentadoras no âmbito internacional como a Organização Internacional do Trabalho (OIT) e da Organização Mundial da Saúde (OMS). Para tanto, o objetivo é analisar os fatores que levam a baixa efetividade da das normas preventivas e punitivas quanto aos acidentes e enfermidades laborais no Brasil.

No ordenamento jurídico brasileiro o cenário não foi construído de forma diferenciada, este se encontra pulverizado por princípios que dão guardia às relações de trabalho. Constituindo-se em um Estado Democrático de Direito, o Brasil é guiado por fundamentos constitucionais que primam pela preservação da Dignidade da Pessoa Humana, como também, pela garantia dos valores sociais do trabalho e da livre iniciativa. Atrelados a tais princípios e estabelecendo-se como segmentos do Direito do Trabalho, a segurança e a medicina do trabalho objetivam oferecer condições de proteção à saúde do trabalhador no local de trabalho e a sua recuperação quando não se encontrar em condições de prestar serviços ao empregador. Dessa forma, vários mecanismos preventivos, punitivos e reparadores são previstos na legislação pátria.

\section{FUNDAMENTAÇÃO TEÓRICA}

\subsection{FUNDAMENTOS CONSTITUCIONAIS PARA A PROTEÇÃO AO TRABALHO: A DIGNIDADE DA HUMANA E OS VALORES SOCIAIS DO TRABALHO E DA LIVRE INICIATIVA}

Os princípios constitucionais são valores fundamentais que fundam a ordem jurídica vigente. São eles que dão coerência ao sistema e servem de critérios de interpretação e integração das normas. Se não fosse a coesão dada pelos princípios, as normas constitucionais só teriam em comum o fato de estarem reunidas em um único corpo. Detém ainda força catalisadora para minimizar as contradições aparentemente existentes entre as normas.

Sob os auspícios desse manto protetor dos princípios encontram-se também as relações trabalhistas. Para tanto, nessa seara deve ser deixada de lado a velha dicotomia que dividia os ramos do Direito em Público e Privado, na qual o Direito do Trabalho ora se encontrava entre as relações privadas, outras vezes integrava as relações públicas. A melhor solução adotada foi o fato de alocar o Direito do Trabalho entre os ramos que regem tanto as relações trabalhistas de caráter público, nas quais o Estado participa, como também, àquelas de feições puramente privadas entre particulares, mas que são também protegidas pelo Poder Público. 
Nesse norte, esclarece Nascimento (2001, p. 70):

É correta essa acepção que aponta a existência de normas publicas e privadas no direito do trabalho. Não considera, todavia, a preponderância destas em relação em face daquelas. As normas púbicas, no direito do trabalho, existem em função dos vínculos de natureza privada.

Aponta-se ainda, uma outra solução que seria enquadrar o Direito do Trabalho como um ramo do Direito Social, que se mostra como sendo uma seara híbrida, na qual mesmo que o Estado não esteja participando da relação jurídica, deve, contudo, protegê-la e garantir o cumprimento dos preceitos constitucionais. Comenta Cesarino Júnior (1980) que esse ramo envolveria todas as normas de proteção às pessoas economicamente fracas, ou seja, os hipossuficientes. Abarcaria não só o Direito do Trabalho, mas ainda o Direito da Previdência Social, dos acidentes do trabalho e de assistência social.

Entendendo-se desse modo a natureza jurídica sui generis do Direto do Trabalho, orientada por princípios constitucionais próprios do Direito Público, e outros, típicos da sua área de atuação como o Princípio da liberdade do trabalho, da organização sindical, norma favorável ao trabalhador, garantias mínimas ao trabalhador, igualdade salarial, direito ao descanso, previdência social, além de outros, merece destaque o papel norteador da Dignidade da Pessoa Humana e dos valores sociais do trabalho e da livre iniciativa que foram the dados.

A Dignidade da Pessoa Humana é valor fundante do Estado Democrático de Direito, encontrando na Constituição Federal de 1988 (CF/88) no art. 1ํ, III. Embora tenha um conteúdo de cunho aparentemente moral, parece que a preocupação do constituinte foi mais de ordem material objetivando proporcionar aos cidadãos, condições dignas de vida principalmente no que tange a vertente econômica e social.

$\mathrm{Na} \mathrm{CF} / 88$ observa-se em vários dos seus dispositivos menção ao Princípio da Dignidade da Pessoa Humana, correlacionado-o à valorização do trabalho. Nesse contexto, percebe-se que, apesar dos ditames da ordem capitalista vigentes no ordenamento jurídico nacional, o trabalho é priorizado como fundamento da dignidade da pessoa humana. Depois de ter perdido a velha conotação de punição que lhe era dado na antiguidade, o trabalho, passou a ser visto como mecanismo essencial tanto para o ser humano considerado individualmente, como também, para toda a coletividade, uma vez que se perfaz como instrumento propulsor para o desenvolvimento da sociedade.

A respeito da abrangência do Princípio da Dignidade da Pessoa Humana na CF/88 esclarece Carvalho (2006, p. 463): 
O princípio abrange não só direitos individuais, mas também os de natureza econômica, social e cultural, pois no estado democrático de Direito a liberdade não é apenas negativa, entendida como ausência de constrangimento, mas liberdade positiva, que consiste na remoção de impedimentos (econômicos, sociais e políticos) que possam embaraçar a plena realização da personalidade humana. Na ordem econômica, vem garantindo quando diz a Constituição que "a ordem econômica , fundada na valorização do trabalho e da livre iniciativa, tem por fim assegurar a todos existência digna conforme os ditames da justiça social (art. 170); na ordem social, quando declara a Constituição que " a ordem social tem por base o primado do trabalho do trabalho, e como objetivo o bem-estar e a justiça social" (art. 193) [...] no artigo $7^{\circ}$ (direitos sociais dos trabalhadores), quando, no inciso IV, institui como direitos dos trabalhadores urbanos e rurais o salário mínimo, fixado em lei, capaz de atendas às suas necessidades vitais básicas e às de sua família: inciso XXX, que proíbe diferença de salários, de exercício de funções e de critérios de admissão por motivo de sexo, idade, cor ou estado civil.

A CF/88 ainda elencou como um dos seus fundamentos os valores sociais do trabalho e da livre iniciativa conforme prescreve o art. $1^{\circ}$, inciso IV. Com o desiderato de alcançar os objetivos almejados na construção de Estado Democrático de Direito e elucidando a importância da vertente social, o trabalho foi alocado entre uma das suas molas mestras. Para tanto ele foi reconhecido através de uma justa remuneração e com condições para o desenvolvimento. Visou também proteger o livre empreendedor, devendo nessa relação jurídica, ser protegido e incentivado pela legislação. Englobando também o trabalhador subordinado, mas também o autônomo exercendo a função de empreendedor para o crescimento do país.

Acerca desse aspecto comenta Carvalho (2006, p. 466):

O trabalho pode ser apreciado sob dois ângulos: individual e social. Por dignificar o homem, a Constituição atribui-lhe relevante valor social, colocando-o assim como um dos fundamentos do Estado Democrático de Direito.

Em outros dispositivos do texto constitucional vigente, foi assegurada a proteção ao trabalho, entre eles cite-se o art. $5^{\circ}$, XXIII quando tratou do livre exercício do trabalho, ofício ou profissão no ordenamento jurídico. Nos arts. $6^{\circ}$ e $7^{\mathrm{o}}$ o referido diploma legal elencou os delineamentos dos direitos sociais que regulamentam as relações laborativas, como também, todos os direitos em espécies dos trabalhadores urbanos e rurais. Já o art. $8^{\circ}$ regulamentou os ditames da organização profissional ou sindical; no art. 196 ao incluir dentre um dos deveres do Estado a saúde, visando a consubstanciação de políticas públicas e econômicas que garantam o acesso a todos; e no art. 204 quando dispôs que as ações governamentais na área da assistência social serão realizadas com recursos do orçamento da seguridade social, incluídas nesta os 
auxílios as vítimas dos infortúnios do trabalho. Além de, no art. 170, visar a construção da ordem econômica, fundada na valorização do trabalho e da livre iniciativa, com o fim assegurar a todos uma existência digna conforme os ditames da justiça social.

Outros fatores devem ser elencados juntamente como as modificações de cunho histórico, social, cultural e principalmente laboral, trazidas pelo fenômeno da globalização oriundas dos efeitos da automação e da informatização, que tem gerado principalmente desemprego crescente e a insuficiência da prestação dos direitos sociais.

Segundo Melo (2008, p. 54):

Tais riscos são agravados diante das diretrizes estabelecidas pelo capitalismo globalizado nos séculos XX e XXI, que não prioriza soluções para as questões sociais e humanitárias. A sua primazia é pelo aspecto econômico que se sobrepõe a qualquer outro.

Tais fatores têm contribuído de maneira prejudicial para implementação de condições dignas de trabalho nos países em desenvolvimento, com o aumento do número de acidentes de trabalho, entre estes países, inclui-se o Brasil.

O escopo da Constituição Federal de 1988 foi a construção de um ordenamento jurídico que tivesse como base o trabalho. Para tanto garantiu a sua proteção de forma ampla, todavia, sem deixar de atender aos ditames do sistema capitalista e de conviver com os preceitos do Estado Social, na busca da melhoria das condições de trabalho.

\subsection{A PROTEÇÃO INTEGRAL AO MEIO AMBIENTE DO TRABALHO NO BRASIL}

Para a exata compreensão das regulamentações quanto aos infortúnios das relações laborais é preciso que se inclua na discussão a definição de meio ambiente do trabalho, entendendo-se este como um conceito mais amplo de meio ambiente que envolve não somente os elementos naturais como a fauna, flora, biosfera, envolve, também, os componentes ambientais humanos. Segundo Rocha (2002, p. 127): “[...] o meio ambiente do trabalho representa todos os elementos, inter-relações e condições que influenciam o trabalhador em saúde física e mental, comportamento e valores reunidos no locus do trabalho".

As relações de trabalho são assim, frutos do meio ambiente, na qual são realizadas e fomentadas por um conjunto de fatores dinâmicos, incluindo não só o aspecto humano e ambiental, mas também o maquinário, a instalação da empresa, dentre outros. Assim, a saúde do trabalhador encontra-se intrinsecamente ligada às relações laborais desenvolvidas no ambiente de trabalho e nele que se buscam as causas e as medidas preventivas dos acidentes e doenças laborais. 
E ainda elucida Ribeiro (2008, p. 21) acerca do escopo da proteção laboral:

\begin{abstract}
Assim, a tutela pretendida não é outra senão a proteção do homem trabalhador, enquanto ser vivo, das várias formas de degradação e poluição do meio ambiente onde exerce seu trabalho, mantendo, pois, o equilíbrio do meio ambiente com a plena saúde do trabalhador, que tem direito a um meio ambiente do trabalho adequado e seguro.
\end{abstract}

Desse modo, o tipo de atividade e o ambiente na qual é realizada são fatores determinantes para a identificação das causas dos acidentes e enfermidades do trabalho. Modernamente, com a globalização e a internet, surgem novas modalidades de trabalho. Dentre elas tem-se o tele-trabalho, realizado em um computador pessoal (em casa ou no estabelecimento empresarial) ou por através da máquina da empresa, ou ainda o trabalho com a genética humana, que condicionam novos ambientes de trabalho que não diminuíram os riscos dos acidentes de trabalho. Diante dessas situações percebe-se que a definição de meio ambiente de trabalho é dinâmica e carece para tanto de constantes aprimoramentos, embora tais reformulações não tenham minimizado os riscos inerentes aos infortúnios do trabalho.

No tocante ao direito ao meio ambiente de trabalho elevado ao status de direito fundamental à saúde, esclarece Silva (2008, p.136):

[...] trata-se a saúde do trabalhador de um direito humano fundamental de natureza negativa e positiva, como já apontado, o qual exige tanto do empregador quanto do Estado não somente a abstenção de práticas que ocasionem a doença física ou mental do trabalhador, mas também uma positividade, isto é, a adoção de medidas preventivas de tal doença. Eis aí os dois aspectos essenciais do mencionado direito: a) o direito à abstenção; b)e o direito à prestação, por sua vez subdividindo em direito à prevenção e direito à reparação.

Tais dispositivos constitucionais, têm também o condão de determinar que o sistema de saúde e o meio ambiente do trabalho devam ser protegidos. Uma vez que o art. 225 caput da $\mathrm{CF} / 88$ ao definir de forma genérica meio ambiente objetivou enquadrar também o meio ambiente do trabalho seguro, adequado, garantindo uma sadia qualidade de vida.

Assim, as normas disciplinadoras do meio ambiente do trabalho não têm sua origem arraigada ao Direito do Trabalho, a sua competência legislativa está incluída entre aquelas comuns da União, dos Estados-Membros do Distrito Federal e dos Municípios conforme prevê o art. 23, VI da CF/88. É um direito difuso, ou seja, disseminado em todo ordenamento jurídico. No mais, os efeitos gerados pela degradação do meio ambiente de trabalho não repercutem apenas no plano individual, mas também na coletividade, já que são sentidos por toda sociedade indistintamente. 
Em termos de proteção legislativa ao meio ambiente do trabalho, além dos dispositivos das Convenções da OIT, as determinações da OMS, da Constituição Federal de 1988, já mencionados, é importante que se destaque o papel do Ministério do Trabalho e Emprego e de seus órgãos governamentais, através do estabelecimento de normas de segurança, higiene e medicina do trabalho por meio da regulamentação feita pela Portaria no 3.214/78; as previsões do Sistema Único de Saúde (SUS), que conte diversos dispositivos relacionados à saúde laboral de acordo com o que prescreve o art. 6oㅡ $\S 3^{\circ}$, Lei no 8.080/90 (Lei Orgânica da Saúde). Enfatizem-se também as disposições feitas pela a Lei de Política Nacional do Meio Ambiente, a CLT, os dispositivos do Código Penal Brasileiro, a Lei dos Crimes Ambientais - Lei n⿳0 9.605/98) e as disposições da Lei n⿳o. 6.938/81 e da Lei no 8.213/91, como também, o ajuizamento dos Dissídios Coletivos de Trabalho.

Depreende-se assim, que o ordenamento jurídico brasileiro tem uma proteção avançada, contemplando inclusive um arcabouço protetivo internacional, no que tange ao meio ambiente do trabalho enquadrando-se aqui a saúde e qualidade de vida do trabalhador, não se restringindo apenas aos dispositivos constitucionais, mas pulverizando todo regramento infraconstitucional.

\subsection{MECANISMOS EFICAZES DE PROTEÇÃO À SAÚDE DO TRABALHOR: ESPÉCIES E PREVISÕES LEGAIS}

Durante muito tempo as atividades laborais eram exercidas de forma desregrada e ofensiva à saúde dos trabalhadores. Em um primeiro momento, isso se dava por falta de conhecimento sobre os riscos das atividades laborais, a posteriori, como o auge da Revolução Industrial, as medidas preventivas aos infortúnios do trabalho não eram efetivadas, em decorrência da ausência de legislação específica e da impossibilidade do operário se afastar da máquina, uma vez que a produção econômica era quem ditava o desenvolvimento da sociedade da época.

Desse modo, percebe-se que a prevenção aos acidentes de trabalho surgiu a partir da construção dos direitos sociais, além da modernização que gerou a necessidade da consubstanciação de normas que melhorassem o ambiente laboral. Observa-se que momento, passaram a existir regras jurídicas sancionadoras e disciplinadoras para o melhoramento do que se passou a designar ambiente do trabalho, como também a regulamentação de condições mínimas a serem observadas pelo empregador no exercício laboral.

No ordenamento jurídico brasileiro, desde a Constituição de 1934, quando foram incorporados formalmente os direitos sociais, já se tratava sobre a segurança e medicina do trabalho. No ano de 1943 foi editado o Decreto-lei $n^{-} 5.452$, de $1^{\mathrm{o}}$ de maio que compilou em um único texto o regramento para as relações jurídicas realizadas no âmbito do Direito do Trabalho que ficou nacionalmente conhecida com CLT. Na Carta Constitucional de 1946 esses preceitos foram ratificados. Em 1966 foi 
editada a Lei no 5.161 que criou a Fundação Centro Nacional de Segurança, Higiene e Medicina do Trabalho. Em 1967 e 1969 foram repetidos os mesmos preceitos.

Já em 1977, os artigos 154 e 201 da CLT foram modificados pela Lei nº. 6.514, incluindo o tratamento, a medicina e a segurança do trabalho. Em 1978 foi editada a Portaria $n^{\circ}$. 3214 que elencou as atividades insalubres e perigosas.

Com a promulgação da Constituição Cidadã de 1988 e a recepção da CLT complementada pela Portaria $\mathrm{n}^{\mathrm{o}} 3.214 / 78$, o tema medicina e segurança do trabalho foi bem esboçado pelo art. $7^{\circ}$, XXII : "São direitos dos trabalhadores urbanos e rurais, além de outros que visem à melhoria de sua condição social: redução dos riscos inerentes ao trabalho, por meio de normas de saúde, higiene e segurança".

No âmbito internacional a OIT vem abordando o tema através de várias convenções, e quase todas estas ratificadas pelo Brasil. Entre elas cite-se a Convenção nº 12 que aborda os acidentes do trabalho na agricultura; a Convenção n ${ }^{0} 115$ de 1960 tratou da radiação; nº113 de 1970 ratificada pelo Brasil em 1991; a Convenção n⿳o 119 de 1963, ratificada pelo Brasil pelo Decreto no $1.255 / 94$ que versa sobre a proteção de máquinas. Tem-se também as Convenções no 127 de 1967, a Convenção no 136 de 1971, ratificada pelo Brasil em 1994 que trata da proteção quanto aos riscos de intoxicação provocada pelo benzeno, dentre outros assuntos; a Convenção no 139 que versou sobre a prevenção e controle dos riscos de substâncias cancerígenas, dentre muitas outras.

$\mathrm{Na}$ busca para a solução dos problemas que envolvem a saúde do trabalhador encontra-se a prevenção. Esta é tida como elo propulsor para a proteção da integridade física e psicológica dos trabalhadores. Ao tema aliem-se vários fatores já que a prevenção garante a redução de gastos, para o empregador, para o Poder Público e para o empregado. A informação foi um veículo importante para a organização nas relações laborais; o melhoramento no meio ambiente do trabalho; o uso obrigatório de equipamentos especiais; a valorização do trabalhador enquanto pessoa portadora de direitos e com dignidade, além de outros mecanismos.

O ordenamento jurídico pátrio tem, atualmente, uma legislação condizente com as inovações tecnológicas no intuito de coibir ou diminuir os acidentes ou enfermidades laborais. A Lei no 6.514/77 alterou os artigos 154 a 201 da CLT que abordam o tema, tendo sido complementada pela Portaria no 3.214/78 que regulamentou a utilização dos equipamentos obrigatórios para a garantia da segurança no trabalho, dentre outras questões.

Dentre eles enfocam-se o papel das Delegacias do Trabalho nas condutas preventivas, o exame médico, os Serviços Especializados em Engenharia de Segurança e Medicina do Trabalho (SESMT); Equipamentos de Proteção Individual (EPIs); as Comissões Internas de Prevenção de Acidentes (CIPAS); o Programa de Controle Médico e da Saúde Ocupacional (PCMSO); Perfil Profissiográfico Previdenciário (PPP); o Programa Preventivo para o melhoramento das condições de 
trabalho (PIACT); O Programa de Prevenção de Riscos Ambientais (PPRA) e a Greve ambiental.

Como regras gerais de prevenção, a CLT elencou no art. 156 o papel das Delegacias do Trabalho nas condutas preventivas, no art. 157, as obrigações da empresa e no art. 158 a função dos empregados para a adoção de tais medidas, denotando assim a necessidade de uma atitude conjunta de todos os entes citados. Assim sendo dispôs a CLT:

Art. 156- Compete especialmente às Delegacias Regionais do Trabalho, nos limites de sua jurisdição:

I - promover a fiscalização do cumprimento das normas de segurança e medicina do trabalho;

II - adotar as medidas que se tornem exigíveis, em virtude das disposições deste Capítulo, determinando as obras e reparos que, em qualquer local de trabalho, se façam necessárias;

III - impor as penalidades cabíveis por descumprimento das normas constantes deste Capítulo, nos termos do art. 201.

Art. 157 - Cabe às empresas:

I - cumprir e fazer cumprir as normas de segurança e medicina do trabalho;

II - instruir os empregados, através de ordens de serviço, quanto às precauções a tomar no sentido de evitar acidentes do trabalho ou doenças ocupacionais;

III - adotar as medidas que lhe sejam determinadas pelo órgão regional competente;

IV - facilitar o exercício da fiscalização pela autoridade competente.

Art. 158 - Cabe aos empregados:

I - observar as normas de segurança e medicina do trabalho, inclusive as instruções de que trata o item II do artigo anterior;

II - colaborar com a empresa na aplicação dos dispositivos deste Capítulo.

Parágrafo único - Constitui ato faltoso do empregado a recusa injustificada:

a) à observância das instruções expedidas pelo empregador na forma do item II do artigo anterior;

b) ao uso dos equipamentos de proteção individual fornecidos pela empresa. Art. 159 - Mediante convênio autorizado pelo Ministério do Trabalho, poderão ser delegadas a outros órgãos federais, estaduais ou municipais atribuições de fiscalização ou orientação às empresas quanto ao cumprimento das disposições constantes deste Capítulo.

A própria CLT ainda estabeleceu que a obediência a esses ditames legais, não desobriga as empresas do cumprimento de outras disposições que, com relação à matéria, sejam incluídas em códigos de obras ou regulamentos sanitários dos Estados ou Municípios, em que se situem os respectivos estabelecimentos, bem como daquelas oriundas de convenções coletivas de trabalho.

Outra medida preventiva elencada entre o rol daquelas da medicina do trabalho é o exame médico. Ele será feito antes da admissão do trabalhador e englobam a avaliação clínica, anamnese ocupacional e o exame físico e mental. De 
acordo com Martins (2002, p. 580), o exame médico “será obrigatório, mas sempre por conta do empregador. O empregado não deverá desembolsar nenhum valor para efeito do exame médico".

Segundo prescreve o art. 168 da CLT, o exame médico deve ser realizado: (i) na admissão; (ii) na dispensa e (iii) periodicamente. Ressalte-se que o médico pode exigir exames complementares para mensurar a capacidade física do empregado para o trabalho a ser realizado. A NR-7 da Portaria $\mathrm{n}^{\mathrm{o}} 3.214 / 78$ trata sobre a periodicidade da avaliação dos exames médicos para as atividades que envolvam riscos maiores à saúde do trabalhador.

Os EPIS (Equipamentos de Proteção Individual) são mecanismos de proteção aos acidentes de trabalho de uso obrigatório nas empresas. A NR-6 da Portaria supra-citada elenca as regras peculiares as EPIs. São comerciáveis mediante certificado de aprovação e estando funcionado perfeitamente. Tais equipamentos de proteção individual podem ser constituídos por vários meios ou dispositivos associados de forma a proteger o seu utilizador contra um ou vários riscos simultâneos.

Segundo Martins (2002, p. 582) as EPIs: “[...] são considerados, entre outros, equipamentos de proteção individual: protetores auriculares (tipo conha ou plug), luvas, mascaras, calçados, capacetes, óculos, vestimentas, etc."

A responsabilidade do empregador, contudo, não se resume ao adquirir os EPIs, engloba também o treinamento do trabalhador para o seu uso, substituição quando o mesmo não estiver mais adequado à utilização e a garantia do seu obrigatório durante a atividade laboral.

A CLT ainda estabelece em seu art. 162 que as empresas, de acordo com o número de funcionários e o grau de risco de suas atividades, devem ter um Serviço Especializado em Engenharia de Segurança e Medicina do Trabalho. Os órgãos de segurança e medicina do trabalho nas empresas, que exigirá a presença de profissionais especializados (médicos e engenheiros do trabalho) nas empresas. Os SESMT (Serviços Especializados em Engenharia de Segurança e Medicina do Trabalho) estão previstos pela NR-4 da Portaria $n^{\circ}$ 3.241/78. Tem-se ainda como legislação regulamentadora o Decreto no 99.530 de 1986 e a Lei no 7.410 de 1985 .

Aos trabalhadores rurais também é garantido a existência dos Serviços Especializados em Prevenção de acidentes do Trabalho Rural (SEPATR) especificado na NR- 2 da Portaria no 3.067/88.

As CIPAs (Comissões Internas de Prevenção de Acidentes) são também mecanismos preventivos aos infortúnios laborais. São regulamentadas pelos arts. 162 a 165 da CLT nos arts. 162 a 165 e pela NR-5, contida na Portaria no 3.214/78. Constituem-se as CIPAs como instrumentos que os trabalhadores dispõem para tratar da prevenção de acidentes do trabalho, das condições do ambiente do trabalho e de todos os aspectos que afetam sua saúde e segurança. 
O escopo da CIPA é integrar empregadores e empregados para que trabalhem conjuntamente na empreitada de prevenir acidentes e melhorar a qualidade do ambiente de trabalho. A organização da CIPA é obrigatória nos locais de trabalho seja qual for sua característica - comercial, industrial, bancária, com ou sem fins lucrativos, filantrópica ou educativa e empresas públicas - desde que tenham o mínimo legal de empregados regidos pela CLT, conforme NR-5.

Ela deverá ser registrada no órgão regional do Ministério do Trabalho até dez dias após a sua eleição, devendo suas atas serem registradas em livro próprio. As CIPAs terão dentre outras atribuições: (i) investigar e analisar os acidentes ocorridos na empresa; (ii) sugerir as medidas de prevenção de acidentes julgadas necessárias por iniciativa própria ou sugestão de outros empregados e encaminhá-las ao presidente e ao departamento de segurança da empresa; (iii) promover a divulgação e zelar pela observância das normas de segurança, ou ainda, de regulamentos e instrumentos de serviço emitidos pelo empregador; (iv) Promover anualmente a Semana Interna de Prevenção de Acidentes (SIPAT), dentre outras.

Outro mecanismo de prevenção aos infortúnios do trabalho adotado pelo ordenamento jurídico brasileiro é o Programa de Controle Médico e da Saúde Ocupacional (PCMSO), que é obrigatório para todos os empregadores e instituições que admitam trabalhadores como empregados.

Conforme Melo (2008) tal programa visa à identificação e ao diagnóstico antecipado de agravos à saúde do trabalhador, inclusive de natureza subclínica, além de verificar a existência de doenças profissionais ou de danos irreversíveis à saúde do trabalhador, devendo para tanto, ser planejado e constituído de acordo com os riscos da saúde do trabalhador e em conformidade com as normas regulamentadoras da Portaria no 3.214/78.

Tem-se ainda nesse cenário de medidas profiláticas, o Perfil Profissiográfico Previdenciário (PPP). Segundo a dicção do Decreto $\mathrm{n}^{\mathrm{o}}$ 3.048/99, art. 68, §8o, acrescentado pelo Decreto n⿳⺈ 4.032/2001:

Considera-se perfil profissiográfico previdenciário, para os efeitos do $\S 6^{\circ}$, o documento histórico-laboral do trabalhador, segundo modelo instituído pelo Instituto Nacional do Seguro Social, que, entre outras informações, deve conter registros ambientais, resultados de monitoração biológica e dados administrativos.

Constitui-se assim o Perfil Profissiográfico Previdenciário (PPP) como um formulário com campos a serem preenchidos com todas as informações relativas ao empregado, como por exemplo, a atividade que exerce o agente nocivo ao qual é exposto a intensidade e a concentração do agente, exames médicos clínicos, além de dados referentes à empresa.

O Programa Preventivo para o melhoramento das condições de trabalho (PIACT), construído pelo OIT na década de 70, visa assessorar os trabalhadores, 
empregadores mundiais, fomentando programas que considerem as peculiaridades de cada país, buscando melhorar as condições de vida e laborais dos trabalhadores.

O Programa de Prevenção de Riscos Ambientais (PPRA) objetiva a preservação da saúde e da integridade física dos trabalhadores, por meio da antecipação, reconhecimento, avaliação e controle da ocorrência de riscos ambientais que permeiam ou venham a permear o ambiente de trabalho, levando em consideração a proteção do meio ambiente e dos recursos naturais. A sua previsão legal contida na NR-9 da Portaria no 3.214/78, como também nos arts. 175 a 178 da CLT.

Ainda se vislumbra nesse cenário profilático dos infortúnios laborais, a greve ambiental como outro meio de profilaxia aos infortúnios do trabalho. Sendo um direito básico do trabalhador tanto na seara coletiva, como na individual é exercitada constantemente pelos trabalhadores para defesa de seus interesses. Por ser um tema inovador, pouco se tratou na doutrina corrente sobre sua conceituação. Fiorillo et. al. (1996, p. 213) a definiu como:

[...] a paralisação coletiva ou individual, temporária, parcial ou total da prestação de trabalho a um tomador de serviços, qualquer que seja sua relação de trabalho, com a finalidade de preservar e defender o meio ambiente do trabalho de qualquer das agressões que possam prejudicar a segurança, a saúde e a integridade física e psíquica dos trabalhadores.

O desiderato da greve ambiental perfaz-se na implantação de condições de trabalho adequadas e seguras, objetivando evitar acidentes e doenças laborais, ou seja, no direito à saúde.

Aponte-se ainda que a saúde dos trabalhadores, atualmente está arraigada entre as prioridades do Estado, e sendo bastante discutidas nos Congressos da OMS. Esta instituição que encabeçou a elevar a saúde do homem a direito fundamental, aliando-se aos princípios da OIT, com as suas Convenções produzidas, a maioria das quais integradas na legislação interna dos países signatários, como o é no ordenamento jurídico brasileiro.

\subsection{OS INSTRUMENTOS DE DEFESA JURÍDICA APLICÁVEIS AOS INFORTÚNIOS DO TRABALHO}

Além dos mecanismos de ordem administrativa, que permeiam o ordenamento jurídico pátrio, há procedimentos na seara judicial que visam além de coibir práticas que sejam propensas à ocorrência dos infortúnios laborais também servem como instrumentos punitivos a tais condutas. Entre eles elenque-se: Termo de Ajustamento de Conduta (TAC); Audiência Pública; Ação Civil Pública Ambiental; Ação Popular; Mandado de Segurança Coletivo, o·Mandado de Injunção e o Dissídio Coletivo. 
O Termo de Ajustamento de Conduta é um instrumento que visa coibir os infortúnios do trabalho. Segundo a dicção do Código de Defesa do Consumidor (Lei $\left.\mathrm{n}^{\mathrm{o}} 8.078 / 90\right)$ que acrescentou o $\S 6^{\circ}$ ao art. $5^{\mathrm{o}}$ da Lei $\mathrm{n}^{\mathrm{o}} 7.347 / 85$, o TAC é um acordo firmado entre o Ministério Público e a parte interessada, de modo que esta se comprometa a agir de acordo com as leis trabalhistas, sob pena de multa. Constituindo-se assim, como, um título executivo extra-judicial, o que significa dizer que seu descumprimento enseja uma ação de execução, proposta pelo Ministério Público do Trabalho junto à Justiça do Trabalho.

As audiências públicas são também instrumentos eficientes na busca de solução dos acidentes de trabalho. Têm base legal no art. 27, inciso IV da Lei Orgânica Nacional do Ministério Público (Lei Federal no 8.625/93) e são instrumentos de grande eficiência em termos de sensibilização e mobilização dos diversos setores de uma comunidade em torno de determinadas questões, ao mesmo tempo em que permitem que a própria comunidade expresse seus anseios e opiniões, proporcionando subsídios aos órgãos incumbidos de propor soluções. No que tange à tutela e prevenção do meio ambiente de trabalho funcionam como instrumentos esclarecedores às partes presentes a respeito das irregularidades nas relações laborais, como também, indicam diretrizes legais a serem seguidas e conseqüências jurídicas das irregularidades. Evitam-se no mais, enxurradas de ações judiciais, pois na maioria das vezes as empresas, que constantemente infringem as dicções legais, adequam-se às normas vigentes espontaneamente.

Regulamentada pelo art. 129, III da CF/88, pelos arts. 83, II e 84, II da Lei Complementar no 75/93, pelo Código de Defesa do Consumidor (Lei no 8078/90) e pela Lei $n^{0} 7.347 / 75$, visa proteger o patrimônio público e social, do meio ambiente e de outros interesses difusos e coletivos. Na seara das relações laborais, busca-se o cumprimento de uma obrigação de fazer ou não fazer, por meio de cominações vultosas em dinheiro, que sirvam de mecanismo inibidor para as irregularidades quanto às relações de trabalho e saúde do trabalhador. Além das demais tutelas de urgência na prevenção e precaução de riscos graves e iminentes para a saúde do trabalhador e da execução. Na Ação Civil Pública Ambiental, acrescenta, com efeito, a condenação por danos genéricos causados ao meio ambiente e à saúde do trabalhador.

Com o mesmo desiderato, a Ação Popular é utilizada na defesa dos interesses difusos. Inclusive, sendo mais antiga do que a Ação Civil Pública, pois remonta ao Direito Romano, no qual era utilizada para a defesa dos interesses difusos. Hodiernamente, é manejada para a defesa das denominadas "coisas do povo". Perfazendo-se como uma forma de garantia da participação democrática do próprio cidadão na vida pública, e está prevista no art. 5으, LXXIII da CF/88, in verbis:

Art. $5^{-}$- [...] omissis

LXXIII -qualquer cidadão é parte legítima para propor ação popular que vise a anular ato lesivo ao patrimônio público ou de entidade de que o 
Estado participe, à moralidade administrativa, ao meio ambiente e ao patrimônio histórico e cultural, ficando o autor, salvo comprovada má-fé, isento de custas judiciais e do ônus da sucumbência.

No tocante à sua utilização da Ação Popular no meio ambiente do trabalho, comenta Melo (2008. p 27):

No meio ambiente do trabalho tal ação pode ser proposta em relação a ato comissivo ou omissivo de empresa pública, empresa de economia mista ou qualquer outro ente público ou pessoa subvencionada pelos cofres públicos, na qualidade de empregador poluidor do ambiente laboral ou em face de atos por eles praticados ou não praticados, a respeito de suas atribuições como órgãos fiscalizadores ou detentores do poder de polícia ambiental.

O rol dos legitimados ativos é mais abrangente, enquadrando-se nessa definição todos aqueles que se adequem ao conceito de poluidor definido pela Política Nacional de Trânsito. O foro competente para o julgamento dessa ação será a Justiça do Trabalho conforme o entendimento dado pela Súmula n.736 do STF.

O Mandado de Segurança Coletivo é também remédio constitucional para a defesa dos direitos dos cidadãos. A CF/88 esboçou a sua regulamentação no art. 5\%, LXIX e LXX, in verbis:

Art 5-- [...] omissis;

[...]

LXIX- conceder-se-á mandado de segurança para proteger direito líquido e certo, não amparado por "habeas-corpus" ou "habeas-data", quando o responsável pela ilegalidade ou abuso de poder for autoridade pública ou agente de pessoa jurídica no exercício de atribuições do Poder Público;

LXX - o mandado de segurança coletivo pode ser impetrado por:

a) partido político com representação no Congresso Nacional;

b) organização sindical, entidade de classe ou associação legalmente constituída e em funcionamento há pelo menos um ano, em defesa dos interesses de seus membros ou associados;

No que diz respeito ao meio ambiente laboral essa ação constitucional pode ser interposta contra o Governador de Estado que praticar ato prejudicial ao meio ambiente do trabalho dos servidores públicos. Se o agente público ou privado no exercício da função pública for poluidor, caberá Mandado de Segurança.

O Mandado de Injunção será manejado do mesmo modo nos infortúnios laborais quando faltar norma regulamentadora que torne inviável o exercício dos direitos e liberdades constitucionais e das prerrogativas inerentes à nacionalidade, à soberania e à cidadania, conforme prescreve o art. 5丷, LXXI da CF/88, desde que atinja as normas omissas das relações laborais. Essa ação foi criada para combater a síndrome da inefetividade das normas constitucionais, visando conferir aplicabilidade imediata às normas omissas. Ressalte-se, que o art. $7^{o}$ da $\mathrm{CF} / 88$ 
regulamentador dos direitos dos trabalhadores está permeado de normas que não têm aplicabilidade imediata.

O Dissídio Coletivo constitui-se em um instrumento de fundamental importância para as relações laborais, já que ninguém melhor para negociar sobre as condições de trabalho que os empregados e empregadores. Essa prática, todavia, é pouco utilizada no Brasil, sobretudo no que tange ao direito ambiental do trabalho. A Constituição Federal de 1988 prevê a sua utilização no $\S 2^{\circ}$ do art. 114 da CF/88 com redação dada pela EC 45/04, in verbis:

Art. $114-[. .$.$] omissis$

$\S 2^{0}$ - o Recusando-se qualquer das partes à negociação coletiva ou à arbitragem, é facultado às mesmas, de comum acordo, ajuizar dissídio coletivo de natureza econômica, podendo a Justiça do Trabalho decidir o conflito, respeitadas as disposições mínimas legais de proteção ao trabalho, bem como as convencionadas anteriormente.

Assim define Melo (2008, p. 139) o Dissídio Coletivo:

[...] uma ação sui generis, por meio dela a Justiça do trabalho "transforma-

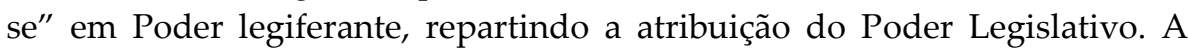
principal diferença em relação a este é que o Poder Judiciário Trabalhista cria a norma para reger situação abstrata de uma dada categoria profissional embora identificada e por prazo determinado.

Todos os instrumentos jurídicos elencados nesse item perfazem um conjunto de medidas que o ordenamento jurídico brasileiro dispõe para coibir e punir os infortúnios laborais, além de prever as formas de reparação deles advindos.

\section{MÉTODOS DA PESQUISA}

Para a construção do presente trabalho, far-se-á uso da metodologia de pesquisa qualitativa, mediante o emprego do método de abordagem hipotéticodedutivo, quando se tomará como hipótese do meio ambiente do trabalho e as medidas profiláticas e punitivas para os acidentes e enfermidades laborais até se chegar à análise dos liames da sua real aplicabilidade nos casos concretos no Brasil, utilizando-se, para tanto, as técnicas de pesquisa bibliográfica e documental, especialmente nas doutrinas que tratam da matéria, como também as diç̧ões normativas nacionais e internacionais que regulamentam que regulamentam a temática em comento.

\section{ANÁLISE DOS RESULTADOS}

A globalização influenciou nesse processo das relações laborais por meio da imposição de novos mecanismos regentes das relações de trabalho e a inserção de 
novas tecnologias inovadoras que ora facilitaram a execução das atividades e a comercialização dos produtos, mas outras vezes afastaram os homens dos postos de trabalho, gerando desemprego. Quanto às medidas preventivas e reparatórias aos infortúnios laborais também se verificou um marcante avanço, principalmente quando se passou a utilizar a máquina para as atividades penosas, insalubres ou perigosas e através da unificação normativa dos órgãos internacionais como a OIT e a OMS encarregados de proteger as relações de trabalho e a saúde dos trabalhadores.

No ordenamento jurídico brasileiro, objetivando maior efetividade é preciso que se providencie a imediata codificação das normas relacionadas à prevenção/punição dos infortúnios laborais; associando-se a esta providência a construção de um canal que fomente no trabalhador a consciência normativa, bem como o conhecimento acerca da existência de programas que viabilizem as medidas profiláticas nesse sentido. Por fim, atrele-se ainda a esses fatores a premente necessidade de uma fiscalização mais eficaz no meio ambiente do trabalho com o desiderato de fazer cumprir todas as normas estabelecidas em sede de segurança e medicina do trabalho.

\section{CONSIDERAÇÕES FINAIS}

As sociedades modernas evoluem diante de um paradoxo constante, especialmente, e perante as relações laborais, pois mesmo com o progresso científico ainda não conseguiu evitar de forma eficaz a ocorrência dos acidentes e enfermidades. Vê-se que diante da adoção de tanta tecnologia e processos mecanizados, não foi possível minimizar de forma satisfatória a ocorrência de danos à saúde do trabalhador.

Um fator importante se observa com a regulamentação dos acidentes e enfermidades laborais para a evolução dos ordenamentos jurídicos mundiais, todavia em se tratando do Brasil, se observa que a normatização ainda não atende satisfatoriamente aos anseios da economia nacional. Até hoje, o cenário protetivo da legislação laboral só tem crescido, inclusive com a adoção da Declaração da OIT sobre os Princípios e Direitos Fundamentais no Trabalho e seu seguimento. Cite-se, também, ao embasamento das regras que norteiam as diretrizes da OMS, além dos Pactos e Tratados internacionais firmados entre os países, inclusive o Brasil, para atribuir aos direitos econômicos e sociais status de direitos fundamentais.

Verificou-se uma evolução gradativa na construção de mecanismos preventivos e punitivos e de cunho reparatório para os infortúnios laborais tanto no ordenamento jurídico pátrio como nos mundiais. A adoção de medidas de segurança no ambiente de trabalho, a criação das CIPAs, a obrigatoriedade da utilização das EPIs, o Perfil Profissiográfico Previdenciário (PPP), o Programa Preventivo para o melhoramento das condições de trabalho (PIACT), O Programa de Prevenção de Riscos Ambientais (PPRA), dentre outros meios, representavam grande avanço 
principalmente quanto à adoção de medidas profiláticas e a compreensão que a responsabilidade dos acidentes causados pelos infortúnios laborais é tanto do empregador do empregado e da sociedade.

Apesar de todas as benesses atreladas aos infortúnios do trabalho no Brasil, verifica-se ainda uma legislação difusa e esparsa nesse ponto, o que muitas vezes dificulta a sua aplicabilidade. A Lei no 8.213/91 com as alterações dadas pela Lei $\mathrm{n}^{\mathbf{0}}$ 11.430/06 que dispõe sobre os Planos de Benefícios da Previdência Social estatizou o seguro acidentário do trabalho no Brasil, mas não regulamentou, a contento, os infortúnios e enfermidades laborais. Não obstante, ainda se verifica uma cobertura deficiente para o empregado lesionado.

\section{REFERÊNCIAS}

BRASIL. Constituição (1988). Manuais de Legislação Atlas. Org. Alexandre de Moraes. 34. ed. São Paulo: Atlas, 2014.

.Constituição (1934). Constituição da República dos Estados Unidos do Brasil de 1934. Disponível em: < http://www.planalto.gov.br/ ccivil_03 /Constituicao/Constitui\%C3\%A7ao34.htm>. Acesso em: 12 set. 2013.

.Constituição (1946). Constituição da República dos Estados Unidos do Brasil de 1946. Disponível em: < http://www.planalto.gov.br/ccivil_03 /Constituicao/Constitui\%C3\%A7ao46.htm >. Acesso em: 12 set. 2013.

BRASIL. Decreto no 1.255 de 29 de setembro de 1994. Promulga a Convenção no ${ }^{\mathrm{o}}$ 119, da Organização Iternacional do Trabalho, sobre Proteção das Máquinas, concluída em Genébra, em 25 de junho de 1963. Disponível em:< http://presrepublica.jusbrasil.com.br /legislacao/112848/decreto-1255-94 >. Acesso em: 29 set. 2013.

.Decreto no 3.048 de 06 de maio de 1999. Altera dispositivos do Regulamento da Previdência Social, aprovado pelo Decreto no 3.048, de 6 de maio de 1999. Disponível em:< http://www.planalto.gov.br/ccivil_03/decreto/D3048.htm>. Acesso em: 26 set. 2013.

Decreto no 4.032 de 26 de novembro de 2001. Altera dispositivos do Regulamento da Previdência Social, aprovado pelo Decreto no 3.048, de 6 de maio de 1999. http://www3.dataprev.gov.br/sislex/paginas/23/2001/4032.htm>. Acesso em: 26 set. 2013. 
BRASIL. Lei no 5.161, de 21 de outubro de 1966. Autoriza a instituição da Fundação Centro Nacional de Segurança, Higiene e Medicina do Trabalho e dá outras providências. Disponível em:< http://presrepublica.jusbrasil.com.br/legislacao/128593/lei-5161-66>. Acesso em: 24 set. 2013.

. Lei no 5.452, de 22 de dezembro de 1977. Altera o Capítulo V do Título II da Consolidação das Leis do Trabalho, relativo a segurança e medicina do trabalho e dá outras providências. Disponível em:< http://www.planalto.gov.br/ccivil_03/leis/16514.htm>. Acesso em: 25 set. 2013.

. Lei no 6.514, de 31 de agosto de 1981. Dispõe sobre a Política Nacional do Meio Ambiente, seus fins e mecanismos de formulação e aplicação, e dá outras providências. Disponível em:< http://www.planalto.gov.br/ccivil_03/leis/16938.htm>. Acesso em: 20 set. 2013.

. Lei no 6.938 , de 31 de agosto de 1981. Dispõe sobre a Política Nacional do Meio Ambiente, seus fins e mecanismos de formulação e aplicação, e dá outras providências. Disponível em:< http://www.planalto.gov.br/ccivil_03/leis/16938.htm>. Acesso em: 20 set. 2013.

Lei $\mathrm{n}^{\mathrm{o}}$ 7.347, de 24 de julho de 1985. Disciplina a ação civil pública de responsabilidade por danos causados ao meio-ambiente, ao consumidor, a bens e direitos de valor artístico, estético, histórico, turístico e paisagístico (VETADO) e dá outras providências. Disponível em: $<\mathrm{http}: / /$ www.planalto.gov.br/ccivil _03/leis/ 17347 orig.htm>. Acesso em: 10 set. 2013.

Lei $\mathrm{n}^{\mathrm{o}}$ 7.410, de 27 de novembro de 1985. Dispõe sobre a Especialização de Engenheiros e Arquitetos em Engenharia de Segurança do Trabalho, a Profissão de Técnico de Segurança do Trabalho, e dá outras Providências. Disponível em:< http://presrepublica.jusbrasil.com.br/legislacao /110240/lei-7410-85 >. Acesso em: 10 set. 2013.

Lei no 8.078, de 19 de setembro de 1990. Dispõe sobre as condições para a promoção, proteção e recuperação da saúde, a organização e o funcionamento dos serviços correspondentes e dá outras providências. Disponível em:< http://www.planalto.gov.br /ccivil_03/leis/18080.htm>. Acesso em: 20 set. 2013.

. Lei $n^{0}$ 8.625, de 12 de fevereiro de 1993. Institui a Lei Orgânica Nacional do Ministério Público, dispõe sobre normas gerais para a organização do Ministério 
Público e dá outras providências. Disponível em: $<$ http://www.planalto.gov.br/ccivil _03/leis/18625.htm>. Acesso em: 20 set. 2013.

Lei n$^{-}$9.605, de 12 de fevereiro de 1998. Dispõe sobre as sanções penais e administrativas derivadas de condutas e atividades lesivas ao meio ambiente, e dá outras providências. Disponível em:< http://www.planalto.gov.br/ccivil_03/leis/19605.htm>. Acesso em: 20 set. 2013.

. Lei $n^{\circ}$ 9.808, de 20 de julho de 199. Define diretrizes e incentivos fiscais para o desenvolvimento regional e dá outras providências .Disponível em:< http://www.planalto.gov.br/ccivil_03/leis/L9808.htm>. Acesso em: 30 set. 2013.

. Lei $n^{\circ}$ 9.605, de 12 de fevereiro de 1998. Dispõe sobre as sanções penais e administrativas derivadas de condutas e atividades lesivas ao meio ambiente, e dá outras providências. Disponível em:< http://www.planalto.gov.br/ccivil_03/leis/19605.htm>. Acesso em: 20 set. 2013.

Lei $\mathrm{n}^{\mathrm{o}}$ 11.430, de 26 de dezembro de 2006. Altera as Leis $\mathrm{n}^{\text {os }} 8.213$, de 24 de julho de 1991, e 9.796, de 5 de maio de 1999, aumenta o valor dos benefícios da previdência social; e revoga a Medida Provisória no 316, de 11 de agosto de 2006; dispositivos das Leis nos 8.213, de 24 de julho de 1991, 8.444, de 20 de julho de 1992, e da Medida Provisória no 2.187-13, de 24 de agosto de 2001; e a Lei no 10.699, de 9 de julho de 2003. Disponível em:< http://www.planalto.gov.br/ccivil_03/_Ato20042006/2006/Lei /L11430.htm>. Acesso em: 20 set. 2013.

BRASIL. Lei Complementar no 73, de 20 de maio de 1993. Dispõe sobre a organização e atribuições e o estatuto do Ministério Público da União. Disponível em:< http://www.planalto.gov.br/ccivil_03/leis/lcp/lcp75.htm>. Acesso em: 25 set. de 2013.

BRASIL. Portaria $\mathrm{n}^{\mathrm{o}} 3.214$ de 08 de agosto de 1978. Aprova as normas regulamentadoras -NR - do Capítulo V, Título II, da Consolidação das Leis do Trabalho, relativas a Segurança e Medicina do Trabalho. Disponível em:<http://portal.mte.gov.br/data/files /FF8080812BE914E6012BE96DD322559 7/p_19780608_3214.pdf . Acesso em: 14 out. 2013.

BRASIL (2012). Regimento Interno do Tribunal Superior do Trabalho. Aprovado pela Resolução Administrativa no 1295/2008,com alterações dos Atos Regimentais nºs 1/2011, 2/2011e 3/2012 e Emendas Regimentais n⿳os 1/2011, 2/2011 e 3/2012. Disponível em:<

http://www3.tst.jus.br/DGCJ/regimento_interno_tst/RegimentoAtualRA1295/Regime ntoInternoRA1295_consolidadaparaimpressao-3.pdf $>$. Acesso em: 20 set. 2013. 
BRASIL (2003). STF. Súmula no 736 de 26 de novembro de 2003. DJ de 9/12/2003 DJ. Disponível em: <http://www.dji.com.br/normas_inferiores/regimento_interno_ e_sumula_stf/stf_0736.htm>. Acesso em: 14 dez. 2013.

CARVALHO, Kildare Gonçalves. Direito Constitucional: Teoria do Estado e da Constituição. Direito Constituição Positivo. 12 ed. rev. e amp. Belo Horizonte: Del Rey, 2006.

CESARINO JÚNIOR, Antônio Ferreira. Direito Social. São Paulo: LTR, 1980.

FIORILLO, Celso Antônio Pacheco; RODRIGUES, Antonio Abelha; ANDRADE NERY, Rosa Maria. Curso de Direito Ambiental Brasileiro. Belo Horizonte: Del Rey, 1996.

MARTINS, Sérgio Pinto. Direito do Trabalho. 15 ed. São Paulo: Atlas, 2002.

MELO, Raimundo Simão de. Direito ambiental do trabalho: responsabilidades legais, dano material, dano moral, dano estético, indenização pela perda de uma chance, prescrição. 3 ed. São Paulo: LTR, 2008.

NASCIMENTO, Amauri Mascaro. Iniciação ao Direito do Trabalho. 21 ed. São Paulo: LTR, 2001.

ORGANIZAÇÃO INTERNCIONAL DO TRABALHO (OIT). Convenção nº 12 Indenização por Acidente do Trabalho na Agricultura. Disponível em: < http://www.oitbrasil.org.br /node /398 >. Acesso em: 13 set. 2013.

Convenção no 113 - Exame médico dos pescadores. Disponível em: < http://www.oitbrasil .org.br/node/473>. Acesso em: 13 set. 2013.

Convenção no 115 - Prevenção contra as radiações. Disponível em: < http://www.oitbrasil.org. br/node/474>. Acesso em: 13 set. 2013.

- Convenção no 119 - Proteção das Máquinas. Disponível em: < http://www.oitbrasil. org .br/node/477 >. Acesso em: 13 set. 2013.

- Convenção no 127 - Peso máximo das cargas. Disponível em: < http://www.oitbrasil .org.br/node/484 >. Acesso em: 13 set. 2013. 
. Convenção no 136 - Proteção Contra os Riscos da Intoxicação pelo Benzeno. Disponível em: < http://www.oitbrasil.org.br/node/490>. Acesso em: 13 set. 2013.

.Convenção no 139 - Prevenção e Controle de Riscos Profissionais Causados por Substâncias ou Agentes Cancerígenos. Disponível em: < http://www.oitbrasil.org.br/node/493>. Acesso em: 13 set. 2013.

RIBEIRO, Juliana de Oliveira Xavier. Auxílio-Doença Acidentário: como ficam o empregado e empregador com o NTEP e o FAP. Curitiba: Juruá, 2008.

ROCHA, Julio César de Sá da. Direito Ambiental do Trabalho: mudança de paradigma na tutela jurídica à saúde do trabalhador. São Paulo: LTR, 2002.

SILVA, José Antonio Ribeiro de Oliveira. A saúde do trabalhador como um direito humano: conteúdo essencial da dignidade humana. São Paulo: LTR, 2008. 